\title{
Influence of Saturated and Polyunsaturated Egg Yolk Phospholipids on Hyperlipidemia in Rats
}

\author{
Katsumi Imaizumi, Masanobu SaKono, Michihiro Sugano, \\ Yasuhiko SHigematsu* and Mineo HaSEgawa* \\ Laboratory of Nutrition Chemistry, Kyushu University School \\ of Agriculture 46, Fukuoka 812, Japan \\ * Research Laboratory, Q.P. Corporation, \\ Fuchu 183, Japan
}

Received March 28, 1989

\begin{abstract}
The supplementation of egg yolk phospholipid (PL) containing phosphatidylcholine (PC) and phosphatidylethanolamine (PE) to a cholesterol-free purified diet causes a reduction in the serum cholesterol level in rats [J. Nutr., 112, 1805 (1982)]. The present study was carried out to determine if dietary egg yolk PL also exerts this hypocholesterolemic action in rats given a high cholesterol diet and if this action is influenced by the constituent fatty acids. Egg yolk PL suppressed the elevation of serum cholesterol irrespective of its fatty acid composition, while purified PC had no effect, suggesting that the ethanolamine portion is responsible for this hypocholesterolemic effect. Egg yolk PL and PC containing longer-chain polyunsaturated fatty acids (arachidonic and docosahexaenoic acids) lowered the serum triglyceride level, while their hydrogenated forms did not. The present results, therefore, indicate that the hypolidemic effect of dietary egg yolk PL can be modulated by the combination of the constituent fatty acids as well as the base moieties. This hypolipidemic effect, however, appeared not to be related to the activities of adipocyte lipoprotein lipase and serum lecithin:cholesterol acyltransferase.
\end{abstract}

In the previous study, soybean phospholipid (PL) or egg yolk PL added to a cholesterol-free diet caused a reduction in the serum cholesterol level in rats. ${ }^{1,2)}$ The phosphatidylethanolamine (PE) contained in these PLs has been demonstrated to be responsible for this hypocholesterolemic action. ${ }^{2,3)}$ More precisely, the consitituent base, ethanolamine, was responsible for lowering of the serum cholesterol level. The major constituent in these PLs, phosphatidylcholine (PC), appeared to be less effective. ${ }^{2,3)}$ Although the mechanism(s) has not been elucidated. PL containing PE suppressed the secretion of cholesterol from perfused liver, ${ }^{4)}$ and increased the plasmic catabolism of $\left[{ }^{3} \mathrm{H}\right]$ oleate-labeled chylomicrons and $\left[{ }^{125} \mathrm{I}\right]-$ labeled-high density lipoproteins. ${ }^{5)}$ These previous results suggest that $\mathrm{PL}$ containing $\mathrm{PE}$ exerts its hypocholesterolemic action by modifying both the secretory and catabolic pathways for serum lipoproteins in normocho- lesterolemic rats.

It is not clear whether or not hypocholesterolemic action of egg yolk PL can be observed even in hypercholesterolemic rats of whether or not the constituent fatty acids influence the hypocholesterolemic action. In the present study, therefore, the effects of hydrogenated and unhydrogenated egg yolk PLs containing PE and phosphatidylcholine (PC) on the serum and hepatic lipid levels were examined in rats given high cholesterol diets. The activities of plasmic lecithin: cholesterol acyltransferase and lipoprotein lipase in adipocytes were also assessed in order to elucidate the mechanism(s) underlying the lipid lowering effect of the dietary PL.

\section{Materials and Methods}

Phospholipid preparations. Crude egg yolk PL was extracted, under stirring in $95 \%(\mathrm{v} / \mathrm{v})$ ethanol, from freeze- 
Table I. Phospholipids and Their Fatty Acios Compositions (wt \%)

\begin{tabular}{lrccc}
\hline & \multicolumn{5}{c}{ Dietary PLs } \\
\cline { 2 - 5 } & PPL & PPLH & PLM & PLMH \\
\hline PL class $^{a}$ & & & & \\
PC & 98.7 & 99.1 & 82.1 & 84.0 \\
PE & - & - & 17.1 & 15.5 \\
SPH & 0.5 & 0.4 & 0.3 & 0.2 \\
LPC & 0.8 & 0.5 & 0.5 & 0.3 \\
\hline Fatty acids & & & & \\
$14: 0$ & 0.2 & 0.1 & 0.2 & 0.1 \\
$16: 0$ & 33.8 & 33.1 & 30.2 & 30.1 \\
$16: 1$ & 1.5 & - & 1.2 & - \\
$18: 0$ & 11.8 & 56.7 & 16.0 & 54.6 \\
$18: 1$ & 30.6 & - & 26.7 & - \\
$18: 2$ & 14.2 & - & 13.7 & - \\
$20: 0$ & - & 4.4 & - & 6.7 \\
$20: 4(n 6)$ & 2.7 & - & 4.9 & - \\
$22: 0$ & - & 5.5 & - & 8.1 \\
$22: 6(n 3)$ & 3.8 & - & 5.2 & - \\
\hline & & & & -
\end{tabular}

a Abbreviations: PC, phosphatidylcholine; PE, phosphatidylethanolamine; SPH, sphingomyelin; LPC, lysophosphatidylcholine.

dried egg yolk and then purified by removing neutral lipids by cold acetone washing (PLM). The PC preparation was obtained from the PLM by passage through a mixed bed resin (PPL). PLM and PPL were hydrogenated by the addition of hydrogen in the presence of palladium (PLMH, PPLH). The compositions of the PL classes and fatty acids used in the present experiment are presented in Table I. PPL and PPLH were composed almost exclusively of $\mathrm{PC}(>99 \%)$. PLM and PLMH contained PE $(15 \sim 17 \%)$ and small amounts of sphingomyelin and lysoPC, and the rest was PC. PLM contained slightly more longer-chain polyunsaturated fatty acids (arachidonic and docosahexaenoic acids) than PPL.

Animals and diets. Male Sprague-Dawley rats, specific pathogen free, were obtained from Seiwa Experimental Animal Co. (Fukuoka). Each rat was individually housed in a wire-meshed cage in a room with controlled temperature $\left(20 \sim 23^{\circ} \mathrm{C}\right)$ and light (lighting, $0800 \sim 2000 \mathrm{hr}$ ). The rats were allowed free access to the control and experimental diets described below and water. Body weight and food intake were recorded every other day. The control diet comprised $10 \%$ corn oil, $1 \%$ cholesterol and $0.25 \%$ NAcholate added to the standardized AIN formula ${ }^{6}$ as shown in Table II. For the experimental diet, $4 \%$ of PL, as shown in Table $\mathbf{I}$, was added to the basal diet at the expense of corn oil. After 28-days feeding all rats were sacrificed by decapitation at $1000 \mathrm{hr}$ without fasting. Liver and epididymal adipose tissues were excised immediately. Blood
Table II. Composition of the Basal Diet

\begin{tabular}{lc}
\hline Ingredients & Weight $\%$ \\
\hline Casein & 20 \\
Fat & 10 \\
Mineral mixture (AIN) & 1.0 \\
Vitamin mixture (AIN) & 3.5 \\
Choline bitartarate & 0.2 \\
Cellulose powder & 5.0 \\
DL-Methionine & 0.3 \\
Cholesterol & 1.0 \\
Na-cholate & 0.25 \\
Corn starch & 15 \\
Sucrose & to 100 \\
\hline
\end{tabular}

serum was separated by centrifugation at $3000 \mathrm{rpm}$ for $15 \mathrm{~min}$.

Determination of the activities of lipoprotein lipase and lecithin: cholesterol acyltransferase. Heparin releasable lipoprotein lipase ad tissue bound lipoprotein lipase activities in the adipose tissues were determined according to the method of Murase et al. ${ }^{7)}$ using $\left[1-{ }^{14} \mathrm{C}\right]$ trioleate ( $50 \mathrm{mCi} / \mathrm{mmol}$ Amersham Japan Co., Tokyo). Serum lecithin:cholesterol acyltransferase activity was determined using a commercially available kit (LCAT-s Nihon Shouji Co., Tokyo).

Lipid analyses. Plasma hepatic lipids were extracted according to the method of Folch et al. ${ }^{8)}$ and measured as described previously. ${ }^{9}$ The fatty acid compositions of hepatic $\mathbf{P C}^{3)}$ were determined by gas-liquid chromatography. ${ }^{10}$

Statistical analyses. Data were analysed by one-way analysis of variace, followed by inspection of all differences between pairs of means at the level of $p<0.05 .^{11}$

\section{Results}

\section{Growth parameters}

Food intake was similar in the groups, but body weight gain tended to be low in rats given hydrogenated PL (PLMH and PPLH), when compared to rats given the control diet and unhydrogenated PL (PLM and PPL) (Table III). The liver weight was significantly lower in rats given hydrogenated $\mathrm{PL}$, when compared to the other groups of rats. The plasmic activity of glutamic-pyruvic transaminase was similar in the groups (data not shown), but the activity of glutamic-oxaloacetic transaminase was significantly lower in all groups fed PL, 
when compared to rats fed the conrol diet $(139 \pm 20,146 \pm 17,149 \pm 10,154 \pm 16$ and $198 \pm 12$ units for PLM, PLMH, PPL, PPLH and the control diet, respectively).

\section{Serum and hepatic lipids}

The serum lipid levels are shown in Table IV. The supplementation of PLM and PLMH suppressed the elevation of the serum cholesterol level, when compared to in the control group. Such an effect was not observed when PPL and PPLH were given. The dietary PLM and PLMH also cecreased the concentration of serum PL. The elevation of the serum triglyceride level was suppressed by the supplementation of the unhydrogenated PL (PLM and PPL). The hydrogenated PL (PLMH and PPLH) did not have such an effect.

Table III. EFFects of Dietary Phospholipids on Growth Parameters

\begin{tabular}{|c|c|c|c|c|}
\hline \multirow{2}{*}{$\begin{array}{r}\text { Dietary } \\
\text { lipids }\end{array}$} & \multicolumn{2}{|c|}{ Body weight } & \multirow{2}{*}{$\begin{array}{l}\text { Food } \\
\text { intake } \\
\text { (g/day) }\end{array}$} & \multirow{2}{*}{$\begin{array}{c}\text { Liver } \\
\text { weight } \\
\text { (g/100g } \\
\text { body wt.) }\end{array}$} \\
\hline & Initial & (g) & & \\
\hline PLM & $161 \pm 3$ & $378 \pm 6$ & $22.8 \pm 0.8$ & $7.1 \pm 0.4^{\mathrm{a}}$ \\
\hline PLMH & $161 \pm 3$ & $356 \pm 15$ & $22.4 \pm 0.7$ & $5.3 \pm 0.2^{b}$ \\
\hline PPL & $161 \pm 4$ & $372 \pm 15$ & $22.3 \pm 0.4$ & $7.0 \pm 0.3^{\mathrm{a}}$ \\
\hline PPLH & $161 \pm 4$ & $352 \pm 12$ & $22.7 \pm 0.8$ & $5.2 \pm 0.2^{b}$ \\
\hline Corn oil & $161 \pm 4$ & $366 \pm 8$ & $22.2 \pm 0.7$ & $7.2 \pm 0.3^{\mathrm{a}}$ \\
\hline
\end{tabular}

Values are means \pm S.E. for six rats per group.

ab Values not sharing common superscript letters are significantly different at $p<0.05$.
The effects of dietary PL on the hepatic lipid levels were different from those on the serum levels (Table IV). The supplementation of hydrogenated PL (PLMH and PPLH) markedly decreased the hepatic cholesterol and triglyceride levels, when compared to the control diet and diets containing unhydrogenated PL (PLM and PPL). The hepatic triglyceride level was slightly, but significantly, lower in rats given PLM and PPL, when compared to in the control group. All the dietary PL caused a reduction in the hepatic level of PL.

\section{Activities of lecithin:cholesterol acyltran-} sferase and lipoprotein lipase

The supplementation of PL did not affect the activity of lecithin : cholesterol acyltransferase, when compared to in the control group, but the enzyme activity in rats given PLMH was significantly higher when compared to in the rats given PPLH (Table V). The PL supplementation did not influence the activities of heparin releasable (extracellular) and residual (intracellular) lipoprotein lipase in adipose tissues when compared to in the control group. A significant difference in the extracellular lipoprotein lipase activity was observed between the rats fed PLMH and PPLH.

\section{Fatty acid composition of hepatic $P C$}

The fatty acid composition of hepatic PC was slightly, but significantly, modified by the constituent fatty acids of dietary PL, as shown

Table IV. Effects of Dietary Phospholipids on the Concentrations of SERUM AND HePATIC LIPIDS

\begin{tabular}{|c|c|c|c|c|c|c|}
\hline \multirow[b]{2}{*}{ Dietary lipids } & \multicolumn{3}{|c|}{ Serum } & \multicolumn{3}{|c|}{ Liver } \\
\hline & $\mathrm{TG}^{1}$ & $\begin{array}{c}\mathrm{PL}^{\mathrm{I}} \\
(\mathrm{mg} / \mathrm{dl})\end{array}$ & $\mathrm{Cho}^{\mathrm{I}}$ & $\mathrm{TG}^{1}$ & $\begin{array}{c}\mathrm{PL}^{1} \\
\text { (mg/g liver) }\end{array}$ & $\mathrm{Cho}^{1}$ \\
\hline PLM & $156 \pm 13^{a}$ & $180 \pm 6^{a}$ & $158 \pm 9^{\mathrm{a}}$ & $123 \pm 2^{a}$ & $18.4 \pm 0.7^{a}$ & $94.7 \pm 5^{a}$ \\
\hline PLMH & $265 \pm 48^{b}$ & $222 \pm 10^{\mathrm{a}}$ & $169 \pm 12^{\mathrm{a}}$ & $65.0 \pm 7^{b}$ & $20.3 \pm 1^{\mathrm{a}}$ & $42.2 \pm 8^{b}$ \\
\hline PPL & $146 \pm 15^{a}$ & $276 \pm 25^{\mathrm{b}}$ & $323 \pm 28^{\circ}$ & $119 \pm 10^{\mathrm{a}}$ & $18.4 \pm 1^{\mathrm{a}}$ & $88.0 \pm 5^{a}$ \\
\hline PPLH & $269 \pm 51^{b}$ & $275 \pm 22^{\mathrm{b}}$ & $251 \pm 33^{\mathrm{b}}$ & $64.3 \pm 5^{b}$ & $19.2 \pm 2^{\mathrm{a}}$ & $37.1 \pm 6^{b}$ \\
\hline Corn oil & $270 \pm 26^{b}$ & $286 \pm 13^{\mathrm{b}}$ & $314 \pm 37^{b}$ & $151 \pm 6^{c}$ & $24.8 \pm 3^{b}$ & $86.5 \pm 4^{a}$ \\
\hline
\end{tabular}

Values are menas \pm S.E. for six rats per group.

1 TG, triglyceride; PL, phospholipid; Cho, cholesterol.

abc Values not sharing common superscript letters are significantly different at $p<0.05$. 
in Table VI. Stearic acid increased on the supplementation of hydrogenated PLs (PLMH and PPLH), when compared to in the control group and on unhydrogenated PL supplementation. Docosahexaenoic acid increased by the dietary unhydrogenated PLs (PLM and PPL). No significant difference in arachidonic acid was observed between the rats given PLs and the control diet.

\section{Discussion}

A hypocholesterolemic action of egg yolk PL has been demonstrated in rats given a cholesterol-free diet. ${ }^{2)}$ The present study showed that the supplementation of PLM and its

Table V. Effect of Dietary Phospholipids on the ACtivities of Lecithin: Cholesterol

ACYLTRANSFERASE (LCAT) AND LIPOPROTEIN LIPASE (LPL)

\begin{tabular}{|c|c|c|c|}
\hline \multirow{2}{*}{$\begin{array}{c}\text { Dietary } \\
\text { lipids }\end{array}$} & \multirow{2}{*}{$\begin{array}{c}\mathrm{LCAT} \\
(\mathrm{nmol} / \mathrm{ml} \cdot \mathrm{hr})\end{array}$} & \multicolumn{2}{|c|}{ LPL } \\
\hline & & $\begin{array}{l}\text { Extracellular } \\
(\mu \mathrm{mol} / \mathrm{mg} \text { we }\end{array}$ & $\begin{array}{l}\text { Intracellular } \\
\text { t wt. } \cdot \min \text { ) }\end{array}$ \\
\hline PLM & $24.2 \pm 6.2^{\mathrm{ab}}$ & $8.5 \pm 3.9^{\mathrm{ab}}$ & $3.8 \pm 0.2$ \\
\hline PLMH & $24.3 \pm 5.4^{\mathrm{a}}$ & $14.9 \pm 3.6^{\mathrm{a}}$ & $3.0 \pm 0.4$ \\
\hline PPL & $21.1 \pm 3.4^{a b}$ & $10.3 \pm 2.2^{a b}$ & $5.3 \pm 1.1$ \\
\hline PPLH & $10.9 \pm 7.5^{b}$ & $5.4 \pm 1.3^{b}$ & $3.8 \pm 0.5$ \\
\hline Corn oil & $16.7 \pm 3.1^{\mathrm{ab}}$ & $8.1 \pm 1.4^{\mathrm{ab}}$ & $2.6 \pm 0.7$ \\
\hline
\end{tabular}

Values are means $\pm S$.E. for six rats per group.

ab Values not sharing common superscript letters are significantly different at $p<0.05$. hydrogenated form, PLMH, to a cholesterolenriched diet partly suppressed the elevation of the serum cholesterol level, when compared to the non-supplemented diet. Therefore, dietary egg yolk PL is effective in decreasing the serum cholesterol level in rats given cholesterolenriched as well as cholesterol-free diets. PPL or its hydrogenated form did not have such an effect. Since PPL is comprised of $99 \%$ of PC and PLM contains $17 \%$ of $\mathrm{PE}$ in addition to $\mathrm{PC}$, it is reasonable to assume the $\mathrm{PE}$ is responsible for this hypocholesterolemic action observed for PLM or its hydrogenated form. Actually, ethanolamine added to the cholesterol-free diet has been repeatedly shown to decrease the serum cholesterol level in rats. ${ }^{2,3)}$

The present study showed that unhydrogenated egg yolk PL preparations (PLM and PPL) suppressed the elevation of the serum triglyceride level. Such an effect was not observed when hydrogenated PL preparations were added to the diets. Longer-chain polyunsaturated fatty acids contained in the egg yolk PLs appeared to be responsible for the hypotriglyceridemic activity, since fish oils containing eicosapentaenoic and docosahexaenoic acids have been shown to exert a strong hypotriglyceridemic action in rats ${ }^{12)}$ and humans. ${ }^{13)}$ Furthermore, it is claimed that longer-chain polyunsaturated fatty acids directly affect hepatic lipid metabolism since,

Table VI. Effect of Dietary Phospholipids on the Fatty Acid Composition of HePatic Phosphatidylcholine (wt $\%$ )

\begin{tabular}{lccccc}
\hline & & \multicolumn{4}{c}{ Dietary lipids } \\
\cline { 4 - 6 } Fatty acids & \multicolumn{1}{c}{ PLM } & PLMH & PPL & PPLH & Corn oil \\
\hline & $21.4 \pm 0.5^{\mathrm{a}}$ & $18.6 \pm 0.4^{\mathrm{b}}$ & $20.8 \pm 1.0^{\mathrm{ac}}$ & $19.2 \pm 0.2^{\mathrm{bc}}$ & $22.2 \pm 0.3^{\mathrm{ac}}$ \\
$16: 0$ & $2.9 \pm 0.2$ & $3.1 \pm 0.3$ & $2.9 \pm 0.4$ & $2.3 \pm 0.1$ & $3.1 \pm 0.4$ \\
$16: 1$ & $11.2 \pm 0.4^{\mathrm{a}}$ & $15.6 \pm 0.4^{\mathrm{b}}$ & $12.3 \pm 1.5^{\mathrm{a}}$ & $15.6 \pm 0.7^{\mathrm{b}}$ & $10.5 \pm 0.9^{\mathrm{a}}$ \\
$18: 0$ & $13.8 \pm 0.6$ & $13.1 \pm 0.3$ & $13.3 \pm 0.8$ & $12.1 \pm 0.3$ & $13.0 \pm 0.7$ \\
$18: 1$ & $16.3 \pm 0.4$ & $14.7 \pm 1.6$ & $14.6 \pm 2.4$ & $13.0 \pm 1.2$ & $15.7 \pm 2.1$ \\
$18: 2$ & $2.9 \pm 0.2$ & $3.6 \pm 0.6$ & $2.4 \pm 0.5$ & $2.1 \pm 0.2$ & $1.7 \pm 0.2$ \\
$20: 3$ & $19.3 \pm 0.8^{\mathrm{a}}$ & $23.2 \pm 1.9^{\mathrm{ab}}$ & $22.1 \pm 2.5^{\mathrm{ab}}$ & $26.9 \pm 1.0^{\mathrm{b}}$ & $25.1 \pm 2.3^{\mathrm{ab}}$ \\
$20: 4(n 6)$ & $6.9 \pm 0.3^{\mathrm{a}}$ & $2.8 \pm 0.3^{\mathrm{b}}$ & $7.1 \pm 0.4^{\mathrm{a}}$ & $3.1 \pm 0.2^{\mathrm{b}}$ & $2.7 \pm 0.3^{\mathrm{b}}$ \\
$22: 6(n 3)$ & & & & &
\end{tabular}

Values are means \pm S.E. for four rats per group.

abc Values not sharing common superscript letters are significantly different at $p<0.05$. 
in cultured rat hepatocytes, the supplementation of eicosapentaenoic acid and, to a leasser extent, docosahexaenoic and arachidonic acids reduced the secretion of very low density lipoproteins by inhibiting cellular triglyceride synthesis, when compared to in the case of oleic acid. ${ }^{14,15)}$ As shown in Table VI, the percentage of docosahexanoic acid in the hepatic $\mathrm{PC}$ was more than two-fold higher in rats given unhydrogenated egg yolk PL (PLM and PPL), when compared to the rats given their hydrogenated froms and the control diet, while the difference in the percentage of hepatic arachidonic acid between the groups was not as evident as in the case of docosahexaenoic acid. Therefore, the hypotriglyceridemic effect of these PLs could be due to the presence of docosahexanoic acid in the PL molecules. The plasmic and hepatic triglyceride levels were essentially similar in the rats fed PLM and PPL, although the former contained more longer-chain polyunsaturated fatty acids (arachidonic and docosahexanoic acids) than the latter. It is not clear at present whether or not arachidonic acid in the dietary PLs contributed to the decreased serum triglyceride levels.

It is interesting to note that the hydrogenated PLs markedly reduced the hepatic accumulation of triglyceride as well as cholesterol. Although the supplementation of egg yolk PLs containing longer-chain polyunsaturated fatty acids also caused a reduction in the hepatic triglyceride level, but not in that of cholesterol, when compared to in the control group, the extent was not as marked as in the case of the hydrogenated PLs. It has been reported that longer-chain saturated fatty acids are poorly absorbed compared with the unsaturated analogs of equivalent chain length. ${ }^{16,17)}$ Therefore, the decreased accumulation of hepatic lipids in rats given these hydrogenated PLs appears to be due to intestinal factors. Interruption of the absorption of dietary lipids by the hydrogenated PLs may also cause the small liver weight in these rats. The decreased utilization of dietary lipids may also explain the tendency of a lower body weight gain in rats given hydrogenated PLs, when compared to unhydrogenated PLs. On feeding intact triglycerides to rodents, however, it was found that stearic acid is better absorbed when it is fed as a mixed triglyceride than when fed as tristearin. ${ }^{18)}$ Therefore, the greater proportion of longer-chain saturated fatty acids, such as eicosanoic and docosanoic acids, in the hydrogenated PL may actually be responsible for these phenomena.

The activities of plasmic lecithin : cholesterol acyltransferase and adipocyte lipoprotein lipase were measured since our previous studies showed that soybean PL given to rats fed a cholesterol-free diet accelerated the in vivo catabolism of chylomicrons ${ }^{4)}$ and the uptake of high density lipoproteins by perfused liver in rats. ${ }^{5)}$ These enzymes are intimately involved in the metabolism of triglyceride ${ }^{19)}$ and cholesterol, ${ }^{20)}$ respectively. As shown in the present study, dietary PLs given to rats fed a high-cholesterol diet do not affect these enzyme activities. Therefore, the hypocholesterolemic and hypotriglyceridemic effects of dietary PLs could not merely be ascribed to the actions of these enzymes. It remains that secretion and/or catabolism of cholesterol and triglyceride in the liver and extrahepatic tissues may be affected in rats given PLs. In fact, secretion of cholesterol by perfused liver has been shown to be suppressed in rats given soybean PL containing PE and PC. ${ }^{31}$

Supplementation of PLs containing PE to cholesterol-free diets consistently causes a reduction in the ratio of arachidonic acid to linoleic acid in the mesenteric lymph $\mathrm{PL},{ }^{21)}$ and plasmic and hepatic PLs in rats. ${ }^{1,3)}$ The reduction in the hepatic microsomal 46 -desaturase activity caused by dietary PLs appears to be responsible for these phenomena (unpublished observation). As shown in Table VI, however, the ratio of arachidonate to linoleate was not altered by the dietary PLs in the present study. Such a discrepancy between the present and the previous results may by due to the presence of cholesterol in the diet, since cholesterol supplementation itself markedly suppresses the 46 -desaturase activity. ${ }^{22\}}$ 
In summary, the present study shows that naturally occurring egg yolk PL containing PE and longer-chain polyunsaturated fatty acids exerts strong hypotriglyceridemic and hypocholesterolemic effects in rats given a highcholesterol diet. Since an egg is the largest single source of cholesterol per gram of food weight that people commonly consume (250 mg per average $\mathrm{egg}^{23 \prime}$ ), the effect of egg consumption on the serum cholesterol level has been extensively examined in human. Roberts et al. came to the conclusion that the feeding of whole eggs, in a double-blind study, to outpatients taking their customary diets had a hypercholesterolemic effect compared to a cholesterol-free product. ${ }^{24)}$ Other investigators did not find any significant changes in the serum cholesterol level with the addition of eggs to the customary diet. ${ }^{25)}$ The present study suggests that the hypercholesterolemic effect of egg cholesterol may be alleviated by the simultaneous presence of egg yolk PL, especially $\mathrm{PE}$.

Acknowledgment. This study was supported in part by the Kiei Kai Research Foundation.

\section{References}

1) K. Imaizumi, M. Murata and M.Sugano, J. Nutr. Sci. Vitaminol., 28, 281 (1982).

2) M. Murata, K. Imaizumi and M. Sugano, J. Nutr., 112, 1805 (1982).

3) K. Imaizumi, K. Mawatari, M. Murata, I. Ikeda and M. Sugano, J. Nutr., 113, 2403 (1983).

4) M. Murata, K. Imaizumi and M. Sugano, J. Nutr., 113, 1708 (1983).

5) M. Murata, K. Imaizumi and M. Sugano, J. Nutr., 115, 994 (1985).
6) American Institute of Nutrition Ad Hoc Committee on Standards for Nutritional Studies, J. Nutr., 107, 1340 (1977).

7) T. Murase, N. Yamada and F. Matsuzaki, Life Sci., 28, 199 (1981).

8) J. Folch, M. Lees and G. H. Sloane-Stanley, J. Biol. Chem., 226, 497 (1957).

9) Y. Nagata, K. Imaizumi and M. Sugano, Brit. J. Nutr., 44, 113 (1981).

10) M. Sugano, K. Ryu and T. Ide, J. Lipid Res., 25, 474 (1985).

11) G. W. Snedecor and W. G. Cochran, "Statistical Methods," 6th Ed., Iowa State University Press, Ames, IA, 1976, pp. 258, 298.

12) S. Wong, M. Reardon and P. Nestel, Metabolism, 34, $900(1985)$

13) S. H. Goodnight, W. S. Harris, W. E. Connor and D. R. Illingworth, Arteriosclerosis, 2, 87 (1982).

14) J. Ø. Nossen, A. C. Rustan, S. H. Gloppestad, S. Málbakken and C. A. Drevon, Biochim. Biophys. Acta, 879, 56 (1986).

15) A. C. Rustan, J. Ø. Nossen, E. N. Christiansen and C. A. Drevon, J. Lipid Res., 29, 1417 (1988).

16) K. K. Carroll, J. Nutr., 64, 399 (1958).

17) R. K. Ockner, J. P. Pittman and J. L. Yager, Gastroenterology, 62, 981 (1972).

18) F. H. Mattson, J. Nutr., 69, 338 (1959).

19) D. S. Robinson and D. R. Wing, "Adipose TissueRegulation and Metabolic Functions," SpringerVerlag, Stuttgart, 1970, p. 41.

20) J. A. Glomset, J. Lipid Res., 9, 155 (1968).

21) K. Imaizumi, M. Murata and M. Sugano, J. Nutr. Sci. Vitaminol., 28, 265 (1982).

22) A. I. Leikin and R. R. Brenner, Biochim. Biophys. Acta, 922, 294 (1987)

23) "Table for Food Content," ed. by S. Innami, T. Sugawara, K. Suzuki and K. Tsuji, Ishiyaku Shuppan Co., Tokyo, 1985, p. 97.

24) S. L. Roberts, M. McMurry and W. E. Connor, Am. J. Clin. Nutr., 34, 2092 (1981).

25) M. A. Flynn, G. B. Nolph, T. C. Flynn, R. Kahrs and G. Krause, Am. J. Clin. Nutr., 32, 1051 (1979). 